\title{
CONTROL FOR A THERMOFORMER USING MATLAB IDENT AND CONTROL TOOLBOX
}

\author{
JUAN J. ARBELAEZ ${ }^{1}$, OSCAR F AVILES ${ }^{2}$, MAURICIO MAULEDOUX ${ }^{3}$ \\ ${ }^{1}$ MATyER Reserch Group, Instituto Tecnológico Metropolitano, ITM. Medellín, Colombia \\ ${ }^{2,3}$ DAVINCI Research Group, Universidad Militar Nueva Granada, Cr 11 No 101-80, Bogotá, Colombia
}

\begin{abstract}
This article presents the process of reconversion and automation of a vacuum thermoforming machine with a single station and manual operation starting from diagnosis, with which the components, capacities, and operation of the systems and their operation as a whole are identified, facilitating the redesign of the mechanical and pneumatic systems and the design of the thermal, electrical and control systems for manufacturing, assembly and commissioning. Thanks to the automated thermoformer, the sequential operation was possible for series work with controlled temperatures, higher levels of heating, reduced energy consumption, and an adequate machine-operator interaction for adjusting the variables and characterizing the thermoforming process on each material. The upgrade and automation proposed for this type of machine represent an alternative of technological capacity with an important potential benefit for small companies in the plastic forming sector.

KEYWORDS: Thermoforming Machine, Mechanical System, Thermal System, Pneumatic System, Electrical And Control System
\end{abstract}

Received: Jun 08, 2020; Accepted: Jun 28, 2020; Published: Sep 30, 2020; Paper Id.: IJMPERDJUN20201457

\section{INTRODUCTION}

Currently, approximately 29.1 million metric tons of thermoplastics are consumed around the world [1]. in injection processes, 3D printing, thermoforming, roto-molding among others. This is because thermoplastics replace metals and other materials in products that require resistance to corrosion, low weight, transparency, selflubrication and economy in manufacturing. Thermoforming is a widely used process in the development of numerous products for the agricultural, medical, food, and locomotion industries, among others, especially in the manufacture of packaging.

Any thermoplastic in sheet form is capable of being thermoformed. The most commonly used polymers are PVC (polyvinyl chloride), PMMA (polymethylmethacrylate), PS (polystyrene), ABS (acrylonitrile butadiene styrene) and PP (polypropylene). Particularly, the more amorphous polymers are, the better behavior during the thermoforming process they show, thanks to their wide processing window and good melt strength [2]. The sheets to be thermoformed are classified into two categories, those of thin gauge with thicknesses close to $1.5 \mathrm{~mm}$ and those of thick gauge with thicknesses close to $3 \mathrm{~mm}$. In the first group, the thermoforming process is carried out on continuous roll feeding machines, mainly for the production of rigid and semi-rigid packaging. In the second category, single-station machines are usually used, fed by a single sheet of dimensions defined by the construction size and used mainly to manufacture panels, decorative and structural components [1]. In general, all 
thermoforming machines are made up of the following elements: sheet handling and clamping mechanisms, oven, devices to generate pressure, vacuum systems, a controller, safety elements and devices for cutting the remaining product.

A particular type of single station thermoforming machine is used by small companies for low production batches or for prototyping. In this type of process, thin gauges are usually used, sometimes slightly higher than $1.5 \mathrm{~mm}$, depending on the capabilities of the machine. A characteristic model of this type of machine is shown in figure 1. In this type of technology, the process begins with the positioning of the mold to be copied on the table and the fixing of the thermoplastic polymer sheet with the help of the clamping frame. The furnace is then heated to the reference temperature and then positioned on the polymer for softening. Subsequently, the heating unit is removed, the table is raised, and the vacuum system is activated to press the mold against the polymer and thus guarantee the copying of the shape. Finally, the motor-fan is activated to cool the material followed by positive pressure in order to separate the thermoformed sheet from the mold, the table is lowered, and the machine is set again in the starting position for a new process.

In single station thermoformers, the thermal system becomes the core of the process, since the control of heat flow through time and temperature variables directly influences the quality of the product under the premises of homogeneity, reduction of material loss and reduction of production costs [3]. The foregoing justifies that significant changes in a thermoforming system should be directed to the automation, regulation and control of material heating [4]. This is why this article presents the design of discrete time controllers for the system shown in figure 1.

In general, this article presents the control design of a thermoforming machine, by vacuum of a single station for automatic operation for temperature control as well as higher levels of heating and greater homogeneity, reduction of energy consumption for commissioning and characterization of the thermoforming process on each material. This type of system is directly aimed at small companies in the plastic forming sector. To obtain the model, a non-parametric identification process is carried out based on experimental data on two different process variables.

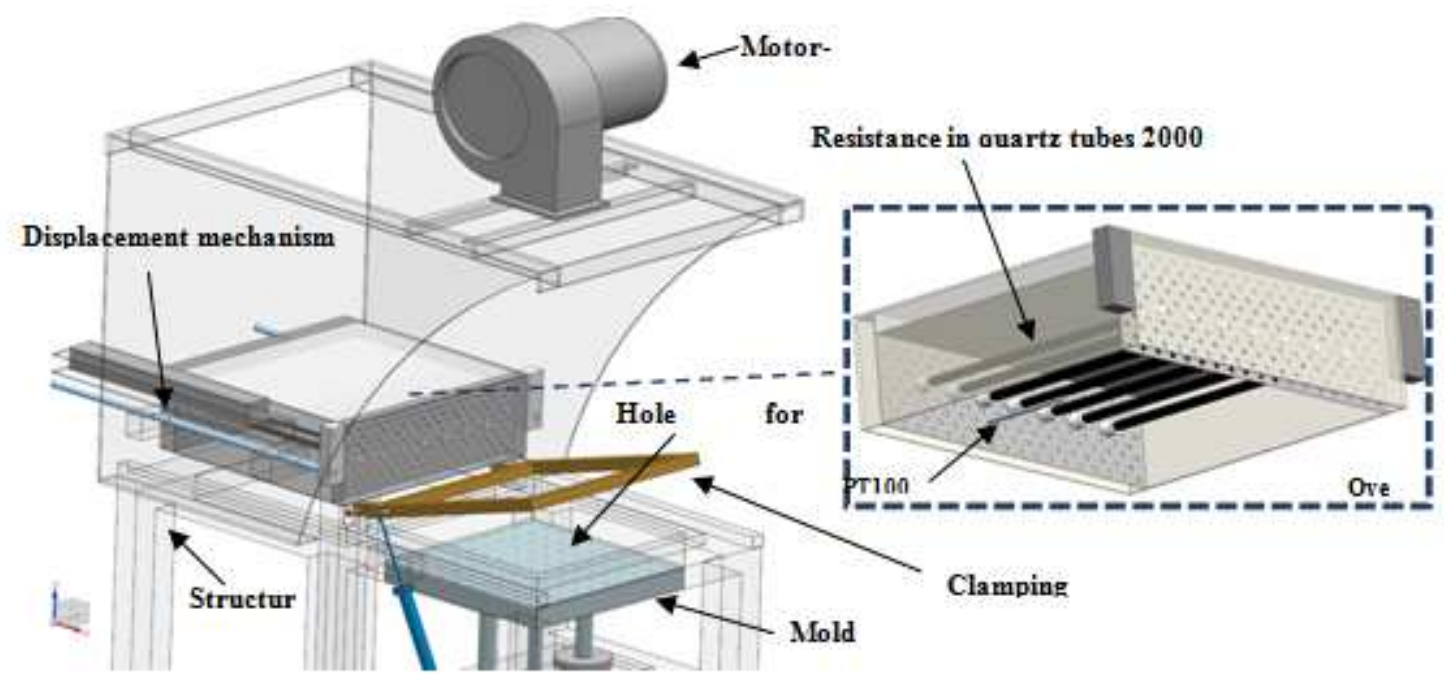

Figure 1: Single station vacuum thermoforming machine structure

\section{METHODOLOGY}

Thermoforming is a process in which a sheet (thermoplastic polymer) is heated to its softening temperature (glass transition). Then, by means of vacuum, air pressure, mechanical force or gravity, the softened polymer is pressed against a mold and rapidly cooled to duplicate its shape. The process ends with the removal of the piece and the trimming of the 
excess material.

Thermoforming is one of the oldest forming processes [5] and is widely used in the production of various products, especially in the development of packaging in the agricultural, medical, food, transportation, construction industries, among others. In 2012, approximately 3.5 billion kilograms of thermoplastic polymers were used around the world. By 2017, approximately 4.25 billion kilograms are expected to be used, distributed in an industry consisting of $20 \%$ in South America, 40\% in China and Southeast Asia, 20\% in India and 20\% in North America [1].

\section{Thermal System}

The machine has a thermal system formed by a thermally insulated sheet box with an ASTM A36 steel plate attached to a reference electrical resistance EL-14321 of $3000 \mathrm{~W}$ at $220 \mathrm{VAC}$, which presents maximum temperatures of $150^{\circ} \mathrm{C}$, with long warm-up times and high energy consumption.

\section{Electric and Control System}

Originally, the system is made up of a Programmable Logic Controller (PLC) together with the power equipment (fan motor, compressor and resistance) directly connected to a three-phase $220 \mathrm{VAC}$ network in addition to the protection elements (pressure switches and thermostat). However, the control system is implemented on an STM card through the Hardware in the Loop methodology.

\section{Thermal System Implementation}

[6] establishes that the most sensitive parameters in the thermoforming process are the material displacement (plug) and the temperature distribution. The first, is subjected to the shape of the piece, while the second, is mainly linked to the heating system. On the other hand, [7] established that the heating of this type of systems must be uniform in the material sheet, to guarantee homogeneity in the copy of the piece.

The new system is constituted by turns of $4.21 \Omega / \mathrm{m}$ nickel-chromium wires whose length generates a power of $2000 \mathrm{~W}$ at $220 \mathrm{VAC}$, inside seven quartz tubes $\left(\varnothing=9 \mathrm{~mm}\right.$ and $\left.\emptyset_{\mathrm{ext}}=12 \mathrm{~mm}\right)$ with the ability to radiate close to $95 \%$ of infrared energy in the range of 1.1 to 2.9 microns, and with ceramic terminals. The entire system was assembled on a perforated structure, made of $1 \mathrm{~mm}$ thick stainless steel and protected by a $2 \mathrm{~mm}$ thick AISI 304 stainless steel container, both pieces separated in the upper part by a thermal insulator and a mirror finish sheet. The temperature sensing can be performed by means of a PT100 thermo-resistance. Figure 2 presents the thermal system before and after the redesign.

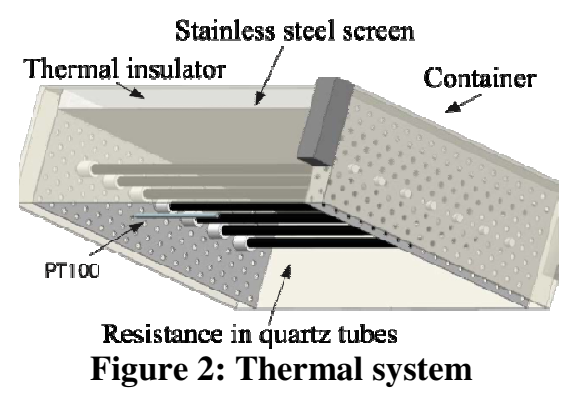

Figure 3. presents the temperature-time curves for the thermal system with the use of two different resistors, one of quartz and the other conventional. The figure shows how the new system reaches temperatures close to twice the temperature of the initial system. This increase in temperature offers the advantage of processing materials with higher 
glass transition temperatures such as SAN (acrylonitrile styrene), Polycarbonate, High-impact Polystyrene, and cell-cast Acrylic, among others. Additionally, for the thermoforming of materials between 130 and $150{ }^{\circ} \mathrm{C}$, the system presents a heating rate of up to eight times that of the previous system and with lower power consumption.

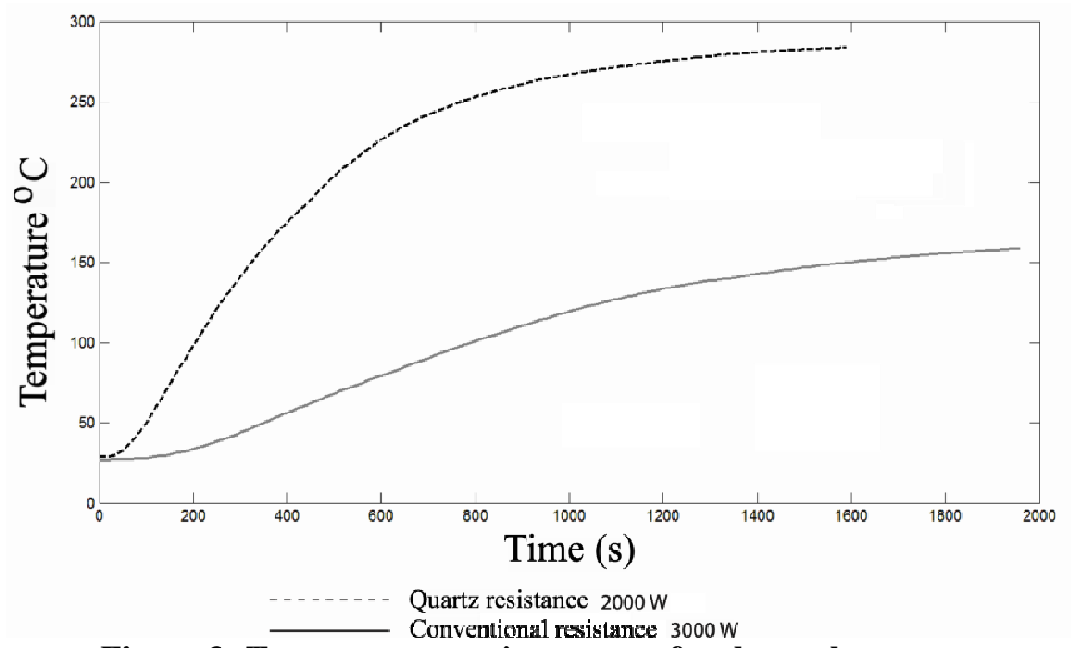

Figure 3: Temperature vs time curves for thermal systems

\section{System Identification and Control}

Identification is an experimental method that allows obtaining the model of a system from real data collected from the plant under study, figure 4. Therefore, identification is the determination, based on the input and output of a system, within a specified class of systems, to which the tested system is equivalent [8].

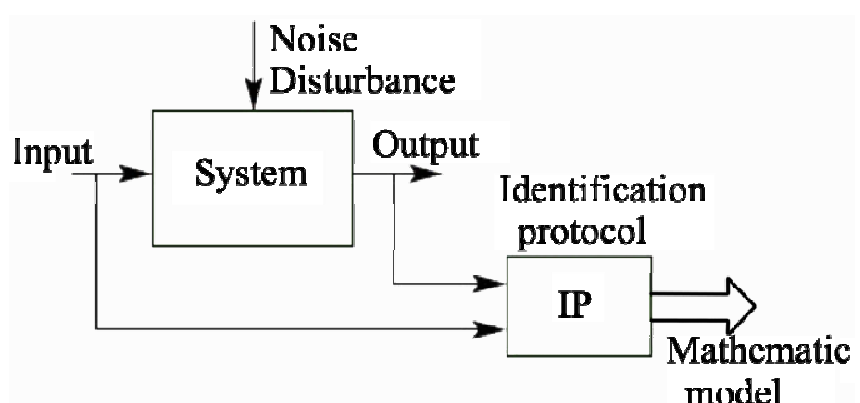

Figure 4: Identification model

To carry out the mathematical model of the process, to which the identification process will be applied, the experimental data that were presented graphically in figure 3. will be used. Two possibilities were considered, a first order system with delay, and a second order system. The following models were obtained, figure 5. 

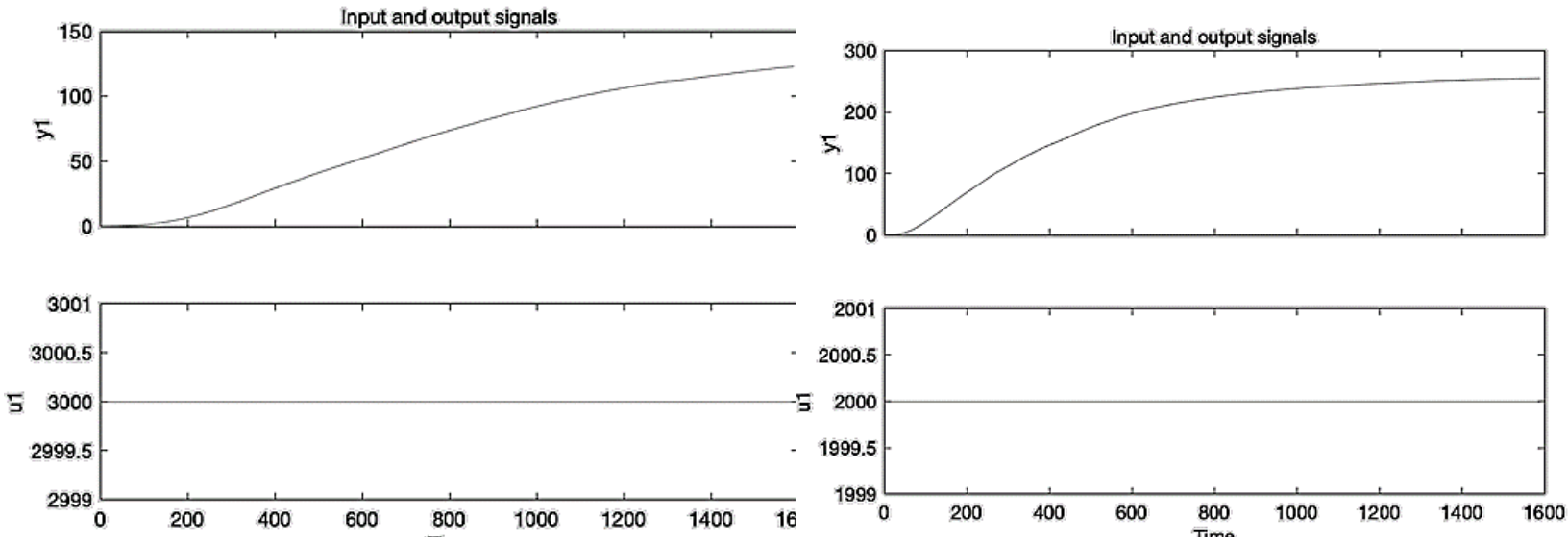

Figure 5: Input and output data for identification
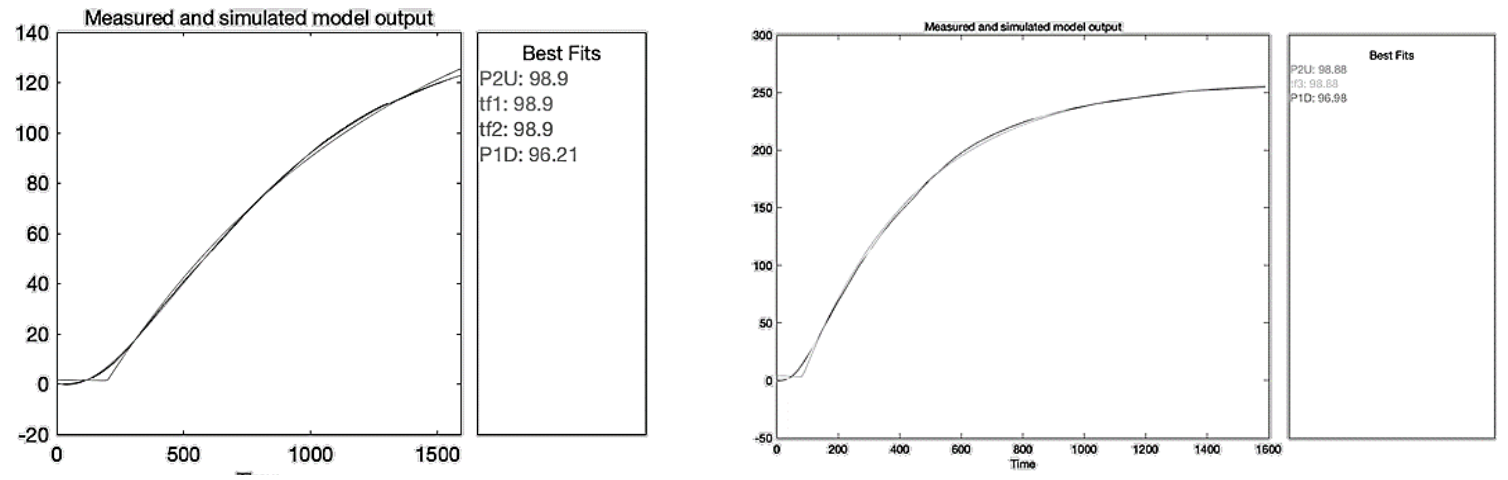

Figure 6: Results of identification with Matlab

First identification, system with conventional resistance (3000W)

First order with delay

$$
\begin{gathered}
G_{1}(s)=\frac{k_{p}}{\tau s+1} e^{T s} \\
k_{p}=0.058827 \\
T_{p 1}=1127.4 \\
T_{d}=198.68
\end{gathered}
$$

Second order

$$
\begin{gathered}
G_{2}(s)=\frac{k_{p}}{1+2 \xi T_{\omega} s+\left(T_{\omega} s\right)^{2}} \\
k_{p}=0.045928 \\
T_{\omega}=430.47 \\
\xi=0.95946
\end{gathered}
$$

Where the model identified in discrete time with a sampling period $T=10 \mathrm{~s}$ will be:

$$
G_{1}(z)=\frac{3.13 \times 10^{-5}-6.81 \times 10^{-6} z^{-1}}{1-1.995 z^{-1}+0.9558 z^{-2}}
$$

For the system with quartz resistance (2000W) we have:

First order with delay

Second order 


$$
\begin{aligned}
G_{1}(s) & =\frac{k_{p}}{\tau s+1} e^{T s} \\
k_{p} & =0.13045 \\
T_{p 1} & =379.81 .4 \\
T_{d} & =83.51
\end{aligned}
$$

$$
\begin{gathered}
G_{2}(s)=\frac{k_{p}}{1+2 \xi T_{\omega} s+\left(T_{\omega} s\right)^{2}} \\
k_{p}=0.12876 \\
T_{\omega}=173.34 \\
\xi=1.2312
\end{gathered}
$$

Where the model identified in discrete time with a sampling period $T=10 \mathrm{~s}$ will be:

$$
G(z)=\frac{0.0003099+8.549 \times 10^{-5} z^{-1}}{1-1.866 z^{-1}+0.8687 z^{-2}}
$$

Whose analysis in frequency and pole or zeros diagram
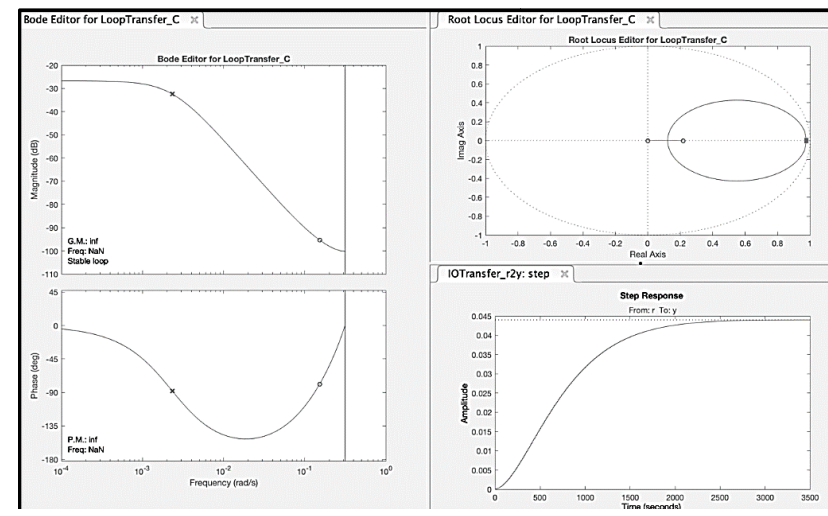

Figure 7: Analysis of pole and zeros in frequency response floor 1

$$
G_{1}(z)=\frac{3.13 \times 10^{-5}\left(1-0.2174 z^{-1}\right)}{1-1.995 z^{-1}+0.9558 z^{-2}}
$$

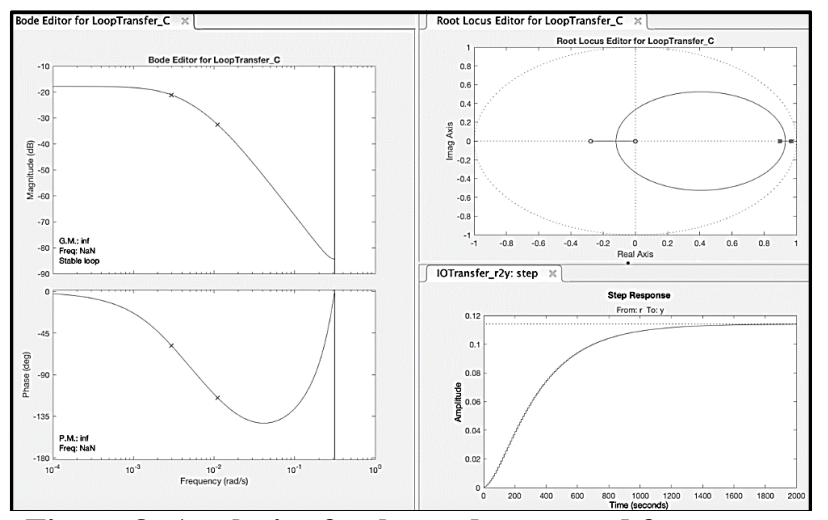

Figure 8: Analysis of poles and zeros and frequency response plant 2

$$
G_{2}(z)=\frac{0.0003099\left(1+0.2759 z^{-1}\right)}{1-1.866 z^{-1}+0.8687 z^{-2}}
$$

A discrete PID with filter is designed for the already optimized plant.

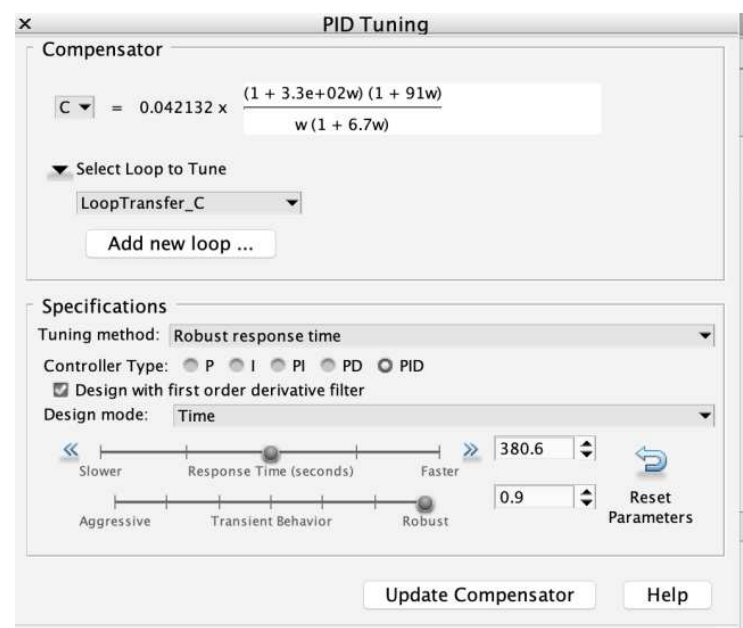

Figure 9: Analysis of poles and zeros and frequency response plant 2 
The plant with the best efficiency now controlled improving its response time thanks to the controller.

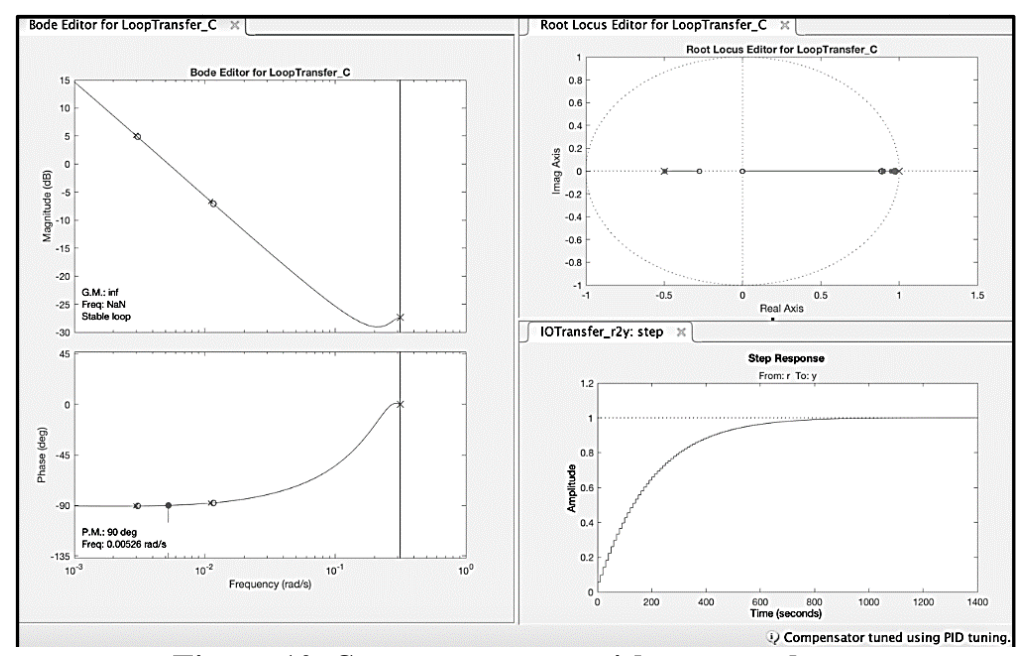

Figure 10: System response without overshoot

$$
G_{c}(z)=\frac{190.39(z-0.9699)(z-0.8897)}{(z-1)(z-0.5004)}
$$

\section{Discrete time PID Controller}

The PID has a proportional part controller which is based on current error, an integral part based on the past error and a derivative part based on future errors. The approximate constants in discrete time were established. For this, there are 3 possible methods which are Euler in advance, Euler in delay and bilinear transformation, this latter being the one used in this work because it offers a smaller error. As this control uses constants that form a discrete filter, a zero order retainer block - $\mathrm{ZOH}$ was used in its simulation to discretize the plant and a quantizer to convert the feedback signal to continuous. A compensator is designed by LGR and BODE using the PID tuning tool to achieve it. The controllers are designed following the architecture in Figure 11.

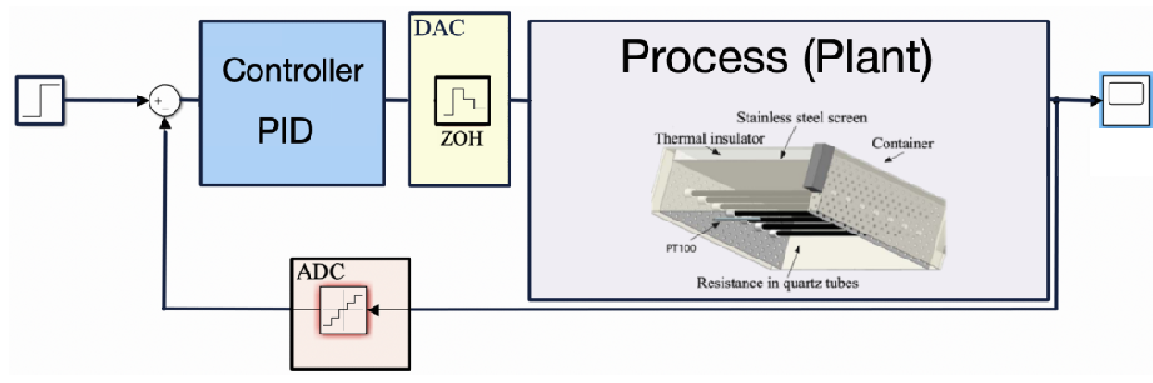

Figure 11: Control system architecture

Using just an integrator and a zero to improve response, only if you have overshoot, which may not be desirable in the warm-up stage 


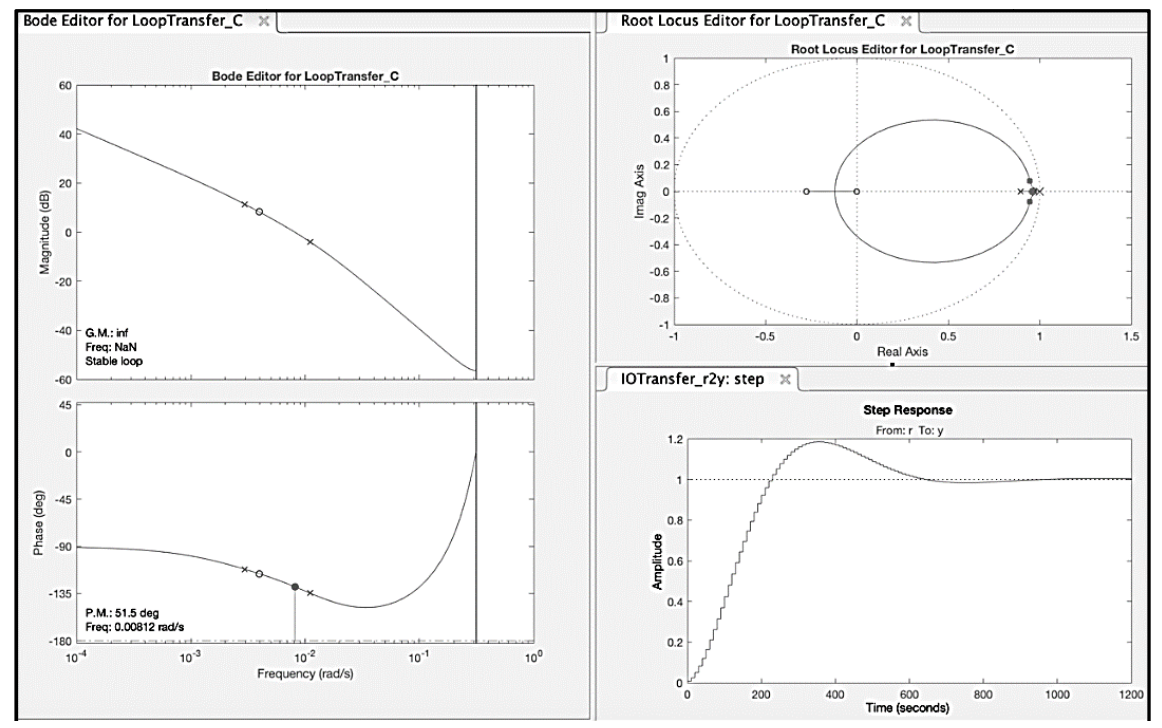

Figure 12: System response with overshoot

$$
G_{c}(z)=\frac{25.707(z-0.9611)}{z-1}
$$

\section{Compensator for LGR with a Single Zero}

The main philosophy that this type of controller follows is to analyze the necessary amount to compensate in margin and profit for our system so that it has the desired behavior. A lead-lag compensator is made by Bode and LGR seeking to cancel the poles of the system. Later, an integrator is added to eliminate the error in steady state as well as a pole with the desired behavior of the plant, thus achieving high performance, without over pulsed and error-free at steady state.

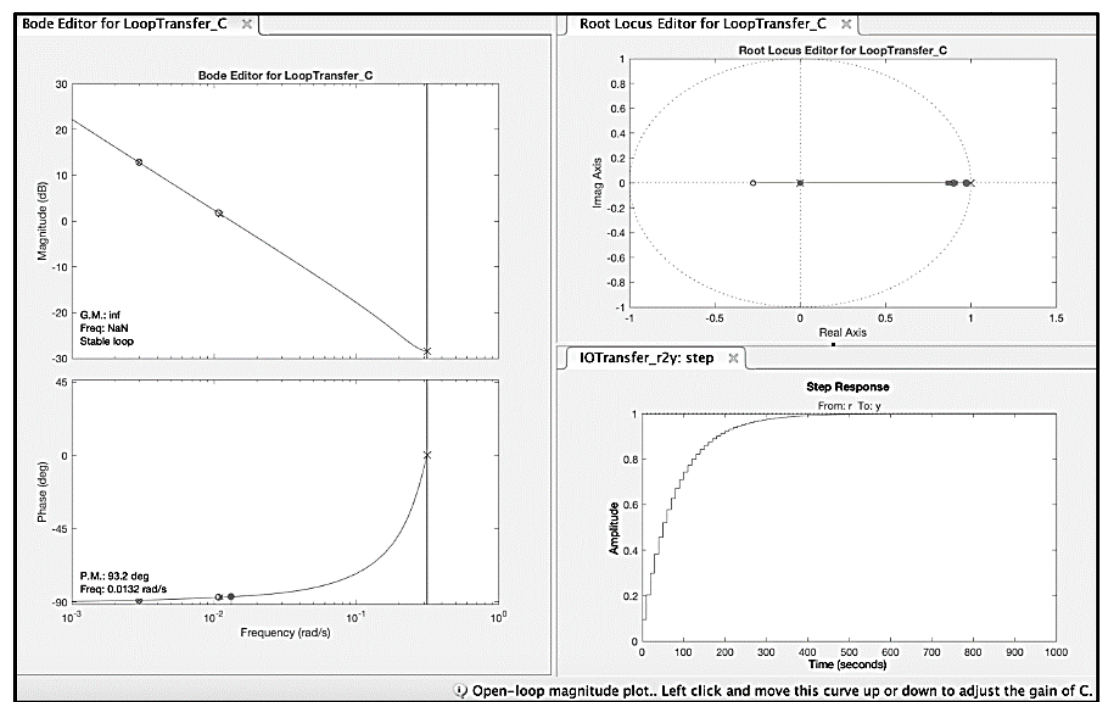

Figure 13: System response with a zero without overshoot

$$
G_{c}(z)=\frac{337.91(z-0.9708)(z-0.8985)}{(z-1)\left(z-4.54 \times 10^{-5}\right)}
$$




\section{Implementation}

The electrical system, and mainly, the control system, are fundamental for autonomous action and programming of processing parameters, according to the characteristics of the material. Different authors present different designs of control systems for thermoformers, all of them with something in common, focused on temperature control, since this is responsible for the rheological behavior of the polymer [9].

To implement an embedded system, a hardware in the loop technique is used to provide an efficient platform to probe systems under control laws. Here, the mathematical model of the system is embedded to emulate its configuration with the control law simulated in the computer software [10]. Therefore, an STM development target and a Matlab interface are used to get the system behavior at different simple times.

\section{CONCLUSIONS}

The control of a single station vacuum thermoforming machine was successfully projected from the implementation of a discrete-PID Controller and a lag lead network. It is shown that the response of the lag-leading network ensures a smooth response, with a good response time and zero position error. The use of Matlab tools ensure that controller development times are shorter. For the final implementation, this is done in an embedded STM system.

\section{ACKNOWLEDGEMENTS}

This work was supported by the Vice-rectory of Research of the Metropolitan Technological Institute of Medellín, through the project "design, reconversion and automatization of a vacuum thermoforming machine with a single station" ('P13107'), with the support of the Davinci Research Group of the Military University Nueva Granada.

\section{REFERENCES}

1. Kutz M. (2011), Applied plastics engineering handbook processing and material. 2nd ed. New York: William Andrew Inc, pp. 95-96

2. Drobney. J. G., Handbook of Termoplastic Elastomers, Norwich: William Andrew Inc, 2007.

3. Klein. P, Fundamentals of Plastics Thermoforming. Synthesis Lectures on Materials Engineering, morgan \& claypool publishers, 2009.

4. Engelman. S, Advanced Thermoforming: methods, Machines and Materials, Applications and Automation (Vol. 8), John Wiley \& Sooins, 2012.

5. Dubois, J. H. (1972). Plastics history. Boston, MA: Cahners Books, pp. 73-74.

6. DiRaddo, R. W., \& Meddad, A. (2000). Sensitivity of operat- ing conditions and material properties for thermo-forming process. Plastics, rubber and composites, 29(4), pp 163-167

7. Zhang, Z. G., Lin, C., Feng, D. K., \& Still, R. (2010). Improving plastic thermoform quality with Uniform Heating Technology. In Advanced Materials Research, 97(1), pp. 204-208

8. Valencia A.J, Linares. N, Mauledoux. M, Avilés. O, "Development of a Toolbox in Matlab for Designing Discrete and Continuous-Time Linear Controllers with System Control Application Using Software in the Loop", International Review of Automatic Control (IREACO), Vol 8. N.6 Praise Worthy Prize. pp. 369 - 374 (2015). ISSN $1974-6059$. doi: http://dx.doi.org/10.15866/ireaco.v8i6.7518 
9. Girard, P., Di Raddo, R., Thomson, V., \& Boulet, B. (2005). Advanced in-cycle and cycle-to cycle on-line adaptive control for thermoforming of large thermoplastic sheets. SAE Technical Paper, [e-journal]. https:// doi.org/10.4271/2005-01-1520.

10. Castañeda, A., Ospina, N., Hurtado, D., Position Control of a Vehicle Seat Using Rapid Prototyping and CAN Protocol, (2015) International Review on Modelling and Simulations (IREMOS), 8 (5), pp. 576-582. 